\title{
Shape Memory Response of Polycrystalline NiTi12.5Hf Alloy: Transformation at Small Scales
}

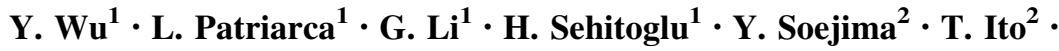 \\ M. Nishida ${ }^{2}$
}

Published online: 24 September 2015

(c) ASM International 2015

\begin{abstract}
The transformation behavior of NiTiHf alloys is intriguing. In NiTiHf alloys, the experimental transformation strains have been reported to be considerably lower than theoretical transformation strains. In this study, the transformation strain is established with very careful strain measurements at small scales in isobaric and isothermal experiments. Because of the heterogeneity of strain distributions, the results depend on the sub-region considered. The measured local transformation strain can be as high as $6.0 \%$ in compression which is in very good agreement with theoretical calculations for NiTi12.5Hf. The comprehension of NiTi12.5Hf alloy was furthered upon extensive microstructural characterization including high-resolution electron microscopy, establishing the volume fractions of precipitates and twin type. The volume fraction of precipitates is similar to that of Ni-rich binary NiTi alloys. Meanwhile, the twinning modes in the martensite are compound and Type I twins which were used in the theoretical calculations of transformation strains. This material also generates a high work output and represents a foundation for understanding higher Hf compositions.
\end{abstract}

Electronic supplementary material The online version of this article (doi:10.1007/s40830-015-0033-0) contains supplementary material, which is available to authorized users.

\section{H. Sehitoglu}

huseyin@illinois.edu

1 Department of Mechanical Science and Engineering, University of Illinois Urbana-Champaign, Urbana, IL 61801, USA

2 Department of Materials Science and Engineering, Kyushu University, Fukuoka, Japan
Keywords Shape memory $\cdot$ Pseudoelasticity $\cdot$ Digital image correlation · Transformation strain · High-resolution electron microscopy

\section{Introduction}

NiTi alloys undergo reversible phase transformations with exceptional shape memory and pseudoelastic behaviors which allow their utilization for a wide range of biomedical and industrial applications [1, 2]. The ternary additions (such as $\mathrm{Hf}, \mathrm{Cu}, \mathrm{Fe}, \mathrm{Pd}$, and others) can improve the functionality of shape memory alloys $[3,4]$ via changing transformation temperatures. However, in most cases, the addition of ternary elements $(\mathrm{Cu}, \mathrm{Fe}, \mathrm{Pd})$ has reduced the transformation strain magnitudes compared to binary NiTi. Experimental results on NiTi20 Hf [5-8] also exhibit lower transformation strain than binary NiTi alloys [9]. In view of the inferior NiTiHf transformation strains measured at macroscale compared to the theoretical values, the question remains whether better agreement can be achieved if experimental strain measurements were made at smaller length scales. In addition, high $\mathrm{Hf}$ compositions are often tested at high temperatures where slip-induced plasticity may curtail the transformation. Studying a lower Hf content such as 12.5 at.\% $\mathrm{Hf}$ could provide a better assessment of transformation strain change with increasing $\mathrm{Hf}$ content. Moreover, precise characterization of the NiTiHf microstructure (precipitate volume fraction and twin modes) is needed. For complete study, the SMA experiments must consider both isobaric temperature cycling (shape memory), and isothermal pseudoelasticity. The strain levels for the two cases may differ because of the ease of plastic flow (or fracture) in pseudoelasticity experiments at higher strains. In this work, we undertake a 
thorough investigation following a multi-scale approach with the aim to provide a better understanding of the transformation strain in NiTi12.5Hf alloy.

The most recent publications in Hf alloyed NiTi have been focused primarily on 20 at.\% $\mathrm{Hf}$ [8] and recently on 25 at. $\%$ Hf compositions [10]. The experimental transformation strains for 20 at. $\% \mathrm{Hf}$ are less than $4 \%$ in most cases compared to theoretical values at $8 \%$. To our knowledge, in the case of NiTi12.5Hf composition, such comparisons have not been reported. Experiments on 12.5 at. $\% \mathrm{Hf}$ are undertaken in the present work, and theoretical strain values are determined. The theoretical transformation strains were established utilizing energy minimization and lattice deformation theories (LDT), and a straightforward comparison between theoretical and measured transformation strains is then presented.

Previous works provided macroscopic strain measurements in NiTiHf over a large domain $(\mathrm{mm})$ measured with an extensometer. The measured transformation strain is thus averaged over a large specimen area containing a large number of grains. These grains are expected to show different transformation strains which are highly orientationdependent in NiTiHf-based alloys. Large strain heterogeneities are thus expected in the polycrystalline alloy, but such heterogeneous nature cannot be captured with classical strain measurement techniques. In this study, we measured transformation strain via digital image correlation (DIC) in order to determine its magnitude at small scales [10]. Local strain measurements via DIC [11] focus only on the grains (or a group of grains) in which transformation develops. The response in this region provides insight into the intrinsic transformation behavior as the surrounding domains remain largely untransformed. In addition to DIC, at smaller length scales, the characterization of the microstructure was achieved by utilizing SEM, TEM, and scanning transmission electron microscopy (STEM) including high-resolution observations to precisely determine the precipitate volume fraction and the type of twin planes.

Because of the importance of precipitation in NiTiHf alloys, we characterize the precipitate volume fraction with three-dimensional microscopy techniques. We also investigate the influence of different aging treatments on the transformation temperatures and transformation strains to achieve the most favorable transformation strain conditions. We focus most of our results on a particular aging treatment and aging temperature $\left(600{ }^{\circ} \mathrm{C} / 100 \mathrm{~h}\right)$ that results in austenite peak temperatures near $90^{\circ} \mathrm{C}$ and precipitate size of $200 \mathrm{~nm}$. The precipitate morphologies and twin interfaces were characterized through high-resolution transmission microscopy. Based on the twin-type observed microscopically (Type I-2 and compound twins), the theoretical transformation strains are computed.
Importantly, with the addition of $\mathrm{Hf}$, the elevation of transformation strains in compression compared to the stoichiometric NiTi is primarily due to the monoclinic angle increase from $97^{\circ}$ for NiTi to $99^{\circ}$ for the NiTi12.5Hf case [12]. The observed localized transformation strains in the present study (near $6 \%$ in compression) confirm this finding. Therefore, it is important to use the NiTi12.5Hf as a foundation for studies of Hf-modified NiTi alloys.

\section{Experiments}

The $\mathrm{Ni}_{51} \mathrm{Ti}_{36.5} \mathrm{Hf}_{12.5}$ alloy investigated in this work was produced by plasma arc melting. The ingots were sectioned into $4 \mathrm{~mm} \times 4 \mathrm{~mm} \times 8 \mathrm{~mm}$ compression samples by electrical-discharged machine. The samples were homogenized in the vacuum chamber for $4 \mathrm{~h}$ at $1000{ }^{\circ} \mathrm{C}$, followed by solution treatment at $900{ }^{\circ} \mathrm{C}$ for $1 \mathrm{~h}$ and quenching in iced water. The samples were successively aged at various temperatures for different time periods. Thin NiTi12.5Hf foils, 40-50 mg, were cut by a low-speed diamond saw for differential scanning calorimetry (DSC) analysis. The surface of the compression specimens was polished by 600- and 1200-grit SiC paper. A fine speckle pattern was then airbrushed onto the surface of the compression specimens for DIC strain measurements. The isothermal and isobaric compression experiments were both conducted on a MTS servo hydraulic load frame. During isothermal experiments, the compression specimens were deformed in displacement control at a strain rate of approximately $10^{-4} / \mathrm{s}$. The load frame was controlled by customized LabView software and images were automatically captured during loading and unloading by an IMB-202FT CCD camera and Navitar optical lens providing a final image resolution of $2 \mu \mathrm{m} / \mathrm{pixel}$. The temperature was controlled by Lepel induction generator through induction coils. The grips were cooled by means of copper wires connected with a liquid nitrogen tank allowing sub-zero cooling. A Raytek infrared sensor was used to monitor the temperature of the specimen. In order to explore the shape memory properties in the isothermal condition, the sample was heated above the austenite finish temperature $\left(A_{\mathrm{f}}\right)$ to ensure complete transformation into austenite state. Subsequently, the temperature was gradually decreased to the test temperature. In isobaric test, images were manually captured during heating and cooling with a temperature step of $5{ }^{\circ} \mathrm{C}$. During the isobaric test for the long-aged heat treatment, the temperature was cycled between 0 and $140{ }^{\circ} \mathrm{C}$. The axial strain fields obtained from these experiments through DIC were used to characterize stress-strain and strain-temperature behaviors of the material. 
Specimens for TEM and SEM were electro-polished by the twin-jet method in an electrolyte solution of $\mathrm{HNO}_{3}$ and methanol $(1: 5, \mathrm{v} / \mathrm{v})$ at about $255 \mathrm{~K}$. The SEM observations were conducted on a Carl Zeiss Ultra 55 system. The focused ion beam slicing and SEM observation were repeatedly performed on a FEI Scios DualBeam system. A FIB slicing interval was set to $5 \mathrm{~nm}$. The successive tomographic images were analyzed with the software Amira (Maxnet, Inc.). Selected-area electron diffraction experiments and TEM observations were carried out on a JEM-2000EX system operated at $200 \mathrm{kV}$. High-angle annular dark-field (HAADF)-STEM observations were performed on a JEM-ARM200F system (Cs-corrected $200 \mathrm{kV}$ STEM). The electron probe size and current were $0.10 \mathrm{~nm}$ and $20 \mathrm{pA}$, respectively. For the HAADF-STEM imaging, the convergence semi angle was fixed to $22 \mathrm{mrad}$. The collection semi angle was set between 90 and 170 mrad.
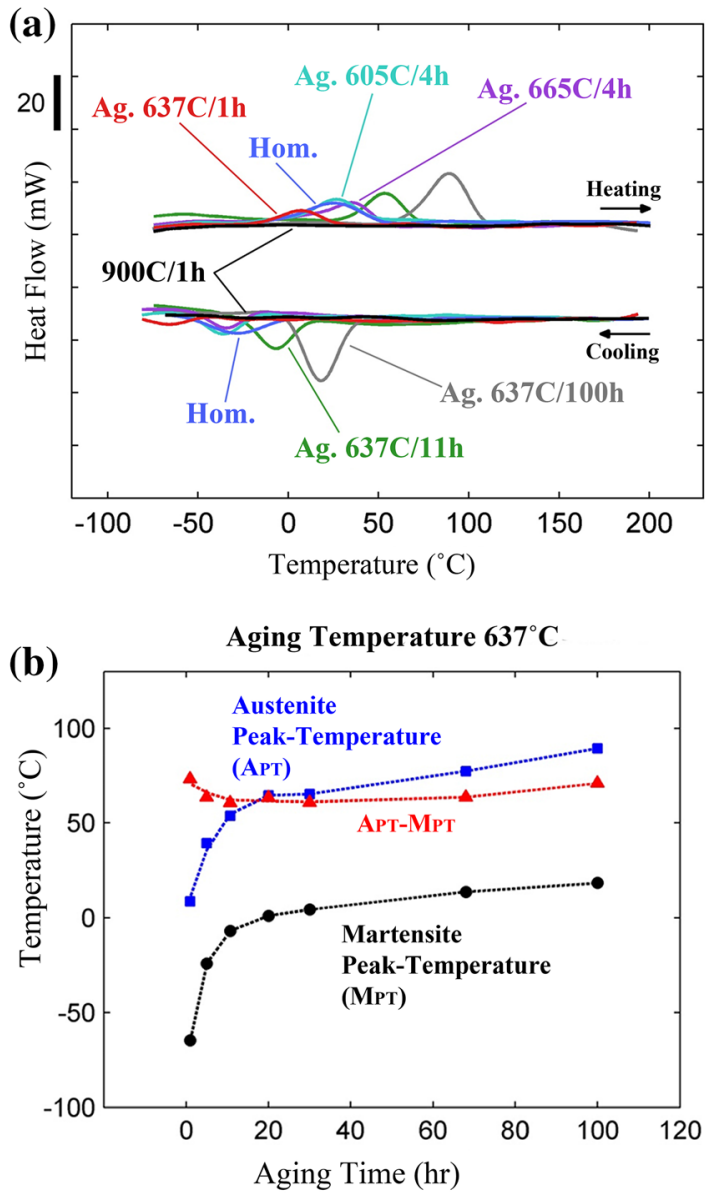

Fig. 1 a DSC curves showing the influence of the most significant heat treatments on the phase transformation temperatures, and $\mathbf{b}$ effect of aging time on austenite $\left(A_{\mathrm{PT}}\right)$ and martensite peak temperatures $\left(M_{\mathrm{PT}}\right)$

\section{Experimental Results}

The most important DSC results are shown in Fig. 1a. Compared to the homogenized case, the transformation temperatures decreased upon solution treatment and subsequent aging at $637^{\circ} \mathrm{C}$ for $1 \mathrm{~h}$. In addition, for the case of $605{ }^{\circ} \mathrm{C} / 4 \mathrm{~h}$ and $665{ }^{\circ} \mathrm{C} / 4 \mathrm{~h}$ heat treatments, the transformation temperatures are still similar to those of the homogenized case. Increment of the transformation temperature can be observed in the long-time aging cases, i.e., $637{ }^{\circ} \mathrm{C} / 11 \mathrm{~h}$ and $637{ }^{\circ} \mathrm{C} / 100 \mathrm{~h}$. In order to investigate the shape memory behavior at the highest temperatures possible, long aging times were chosen (the gray curve in Fig. 1a). In Fig. 1b, the influence of the aging time on the $A_{\mathrm{PT}}$ and $M_{\mathrm{PT}}$ temperatures is presented for a fixed aging temperature $637{ }^{\circ} \mathrm{C}$. Both $A_{\mathrm{PT}}$ and $M_{\mathrm{PT}}$ increase from 1 to $15 \mathrm{~h}$ of aging. $M_{\mathrm{PT}}$ increases faster than $A_{\mathrm{PT}}$ resulting in a big drop of hysteresis, $A_{\mathrm{PT}}-M_{\mathrm{PT}}$, at the lower aging time range. The hysteresis, $A_{\mathrm{PT}}-M_{\mathrm{PT}}$, shows a minimum at $10 \mathrm{~h}$ aging and increases slightly with further aging time.

In Fig. 2, precipitation in the material matrix for the case of $637{ }^{\circ} \mathrm{C} / 100 \mathrm{~h}$ was captured through SEM. Based on the volume fraction of particle in grains 1 and 2, the overall volume fraction was calculated to be approximately $20 \%$. The cross-section shape of the precipitate is oblate spindle like as shown in (b) and (c), which is also similar to the one reported for Ti-rich NiTiHf after $150 \mathrm{~h}$ of aging [13]. However, the overall shape of the precipitate can be more complicated as shown in Fig. 3. The size of the precipitate is measured as approximately $200 \mathrm{~nm}$. These facts are also confirmed by three-dimensional visualization of the

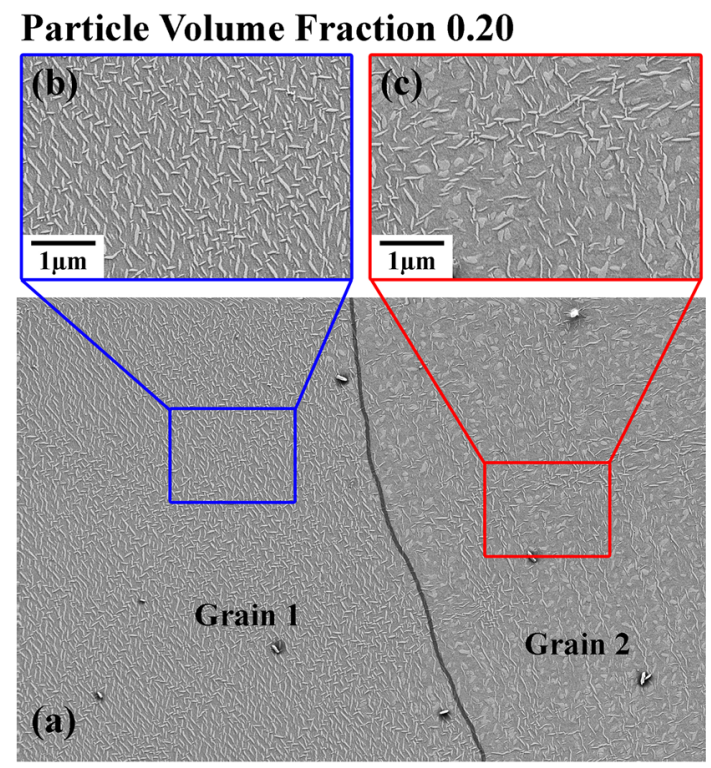

Fig. 2 a Secondary electron image showing precipitation distribution in $\mathrm{Ni}_{51} \mathrm{Ti}_{36.5} \mathrm{Hf}_{12.5}$ aged at $637^{\circ} \mathrm{C} / 100 \mathrm{~h}$. b and c Enlarged images captured from the framed areas in a 
precipitate structure (movie is included as a supplement) in Fig. 3.

Isobaric experiments (Fig. 4) were conducted under different applied compressive loads. In Fig. 4, we also report the strain fields at the minimum temperature of each thermal cycle under the specific compressive stress. The strain fields were obtained using the reference image captured at the maximum temperature and zero stress. The

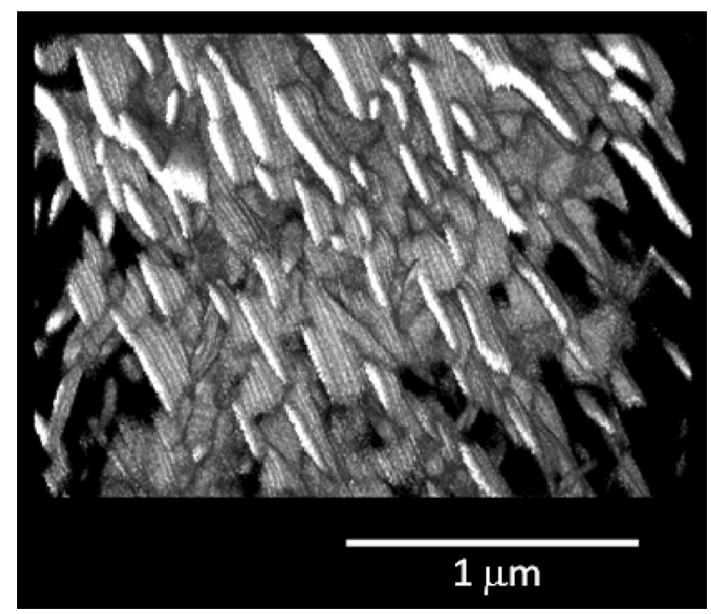

Fig. 3 Three-dimensional visualization of the precipitate structure (movie is included as a supplement) solid line was determined averaging the axial strain fields over all DIC region $(4 \mathrm{~mm} \times 3 \mathrm{~mm})$. It is worth pointing out the heterogeneous nature of the strain fields where low and high strains are exhibited at small scales. The heterogeneity of the strain distribution is mainly due to the fact that finite volumes retain their austenitic structure. This observation is further confirmed with X-ray diffraction of the samples based on the B2 peaks. In order to quantify the maximum transformation strain in the straintemperature plots, we also include the curve representing the local temperature-strain behavior of the region that displays the largest strain localization (dashed line). The area which was used to collect localized data is shown in the strain contour plots by a black box. Besides, the red line and blue line represent heating and cooling, respectively. From 0 to $500 \mathrm{MPa}$ applied stress, negligible irreversibility was measured either for the averaged strains over the DIC region or for the local. The maximum local transformation strain was obtained to be $5.5 \%$ at $500 \mathrm{MPa}$. The hysteresis was found to be approximately $40{ }^{\circ} \mathrm{C}$. In addition, the transformation temperatures will also tend to increase with increasing of applied stress. According to Fig. 4, when the applied stress is $0 \mathrm{MPa}, M_{\mathrm{f}}, M_{\mathrm{s}}, A_{\mathrm{s}}$, and $A_{\mathrm{f}}$ are $20,35,50$, and $70{ }^{\circ} \mathrm{C}$, respectively. All the temperatures increase by $15^{\circ} \mathrm{C}$ when a $500 \mathrm{MPa}$ stress is applied. The trend matches with the

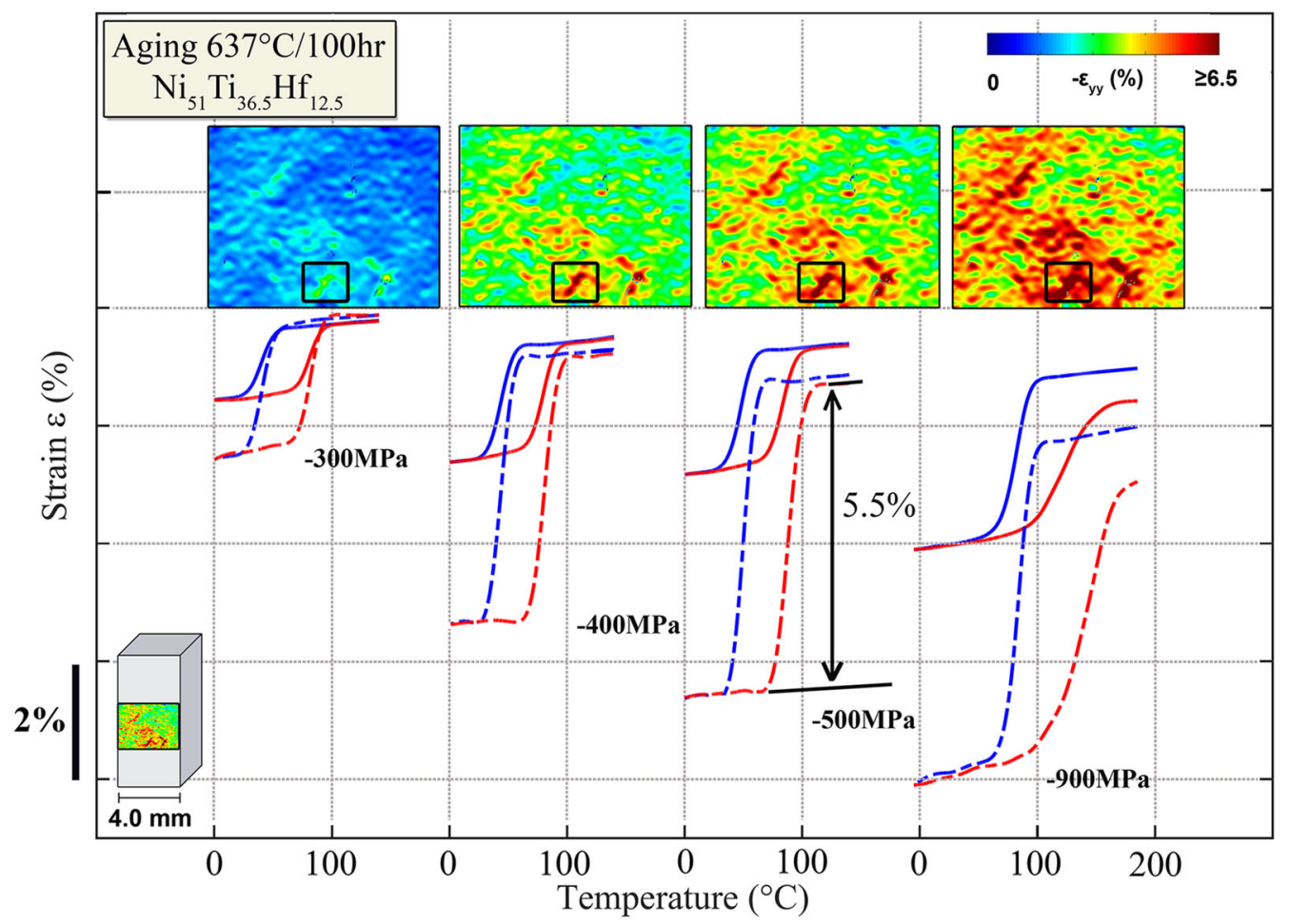

Fig. 4 Isobaric tests at various compressive stresses for the $\mathrm{Ni}_{51}$ $\mathrm{Ti}_{36.5} \mathrm{Hf}_{12.5}$ alloys aged at $637{ }^{\circ} \mathrm{C} / 100 \mathrm{~h}$. The corresponding DIC temperature of the thermal cycle. The boxes displayed in the DIC strain fields indicate the region used to calculate the local strains and the corresponding strain-temperature curves (dashed line) 

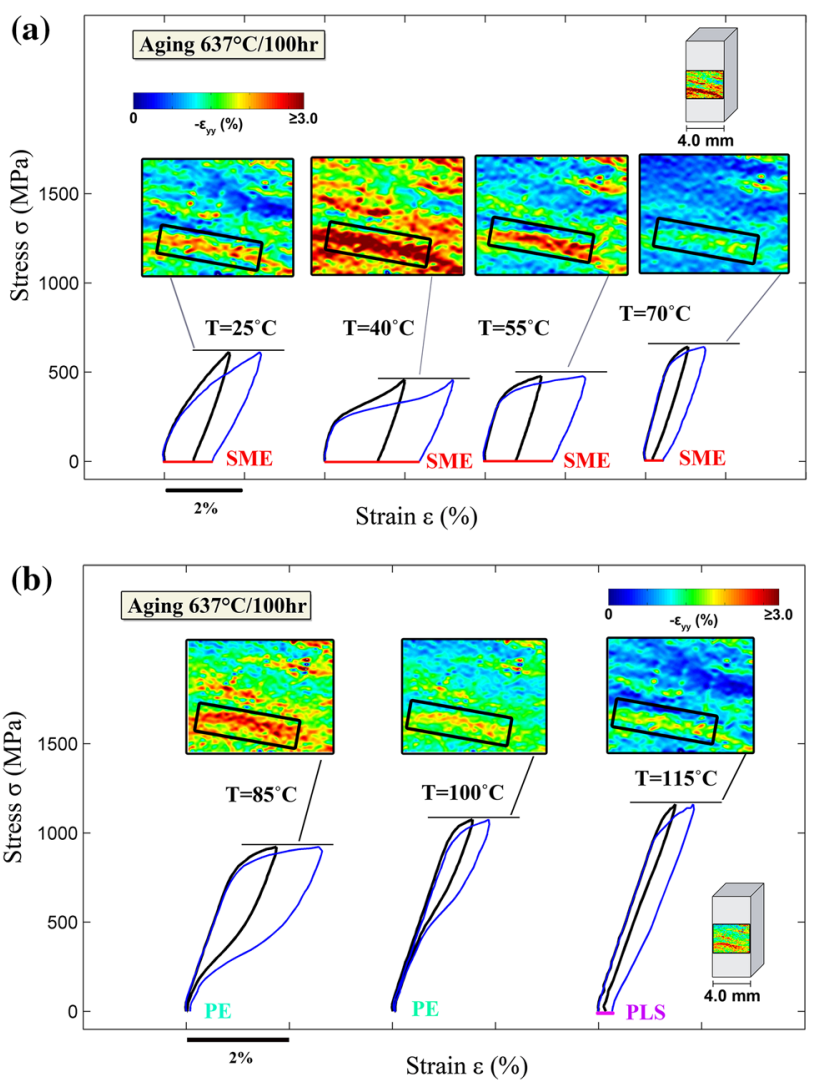

Fig. 5 Stress and strain relationship at various temperatures in which a shape memory effect (SME) dominates and b pseudoelasticity (PE) and plasticity (PLS) dominate. The local in situ strain measurement (blue curves) was extracted from the strain fields delimitated by the boxes displayed in the DIC images

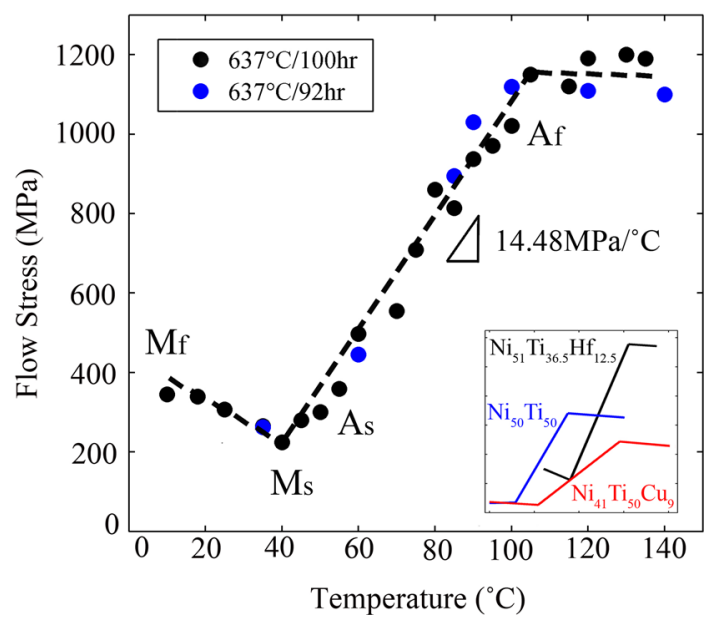

Fig. 6 Flow stress as a function of temperature when the $\mathrm{Ni}_{51} \mathrm{Ti}_{36.5-}$ $\mathrm{Hf}_{12.5}$ is heat treated at $637^{\circ} \mathrm{C} / 100 \mathrm{~h}$ and $637^{\circ} \mathrm{C} / 92 \mathrm{~h}$. The inset shows $\mathrm{NiTi}$ and $\mathrm{NiTiCu}_{9}$ for comparison

other experimental results published in the literature [7]. However, the thermal hysteresis stays relatively stable at a level of $40{ }^{\circ} \mathrm{C}$.

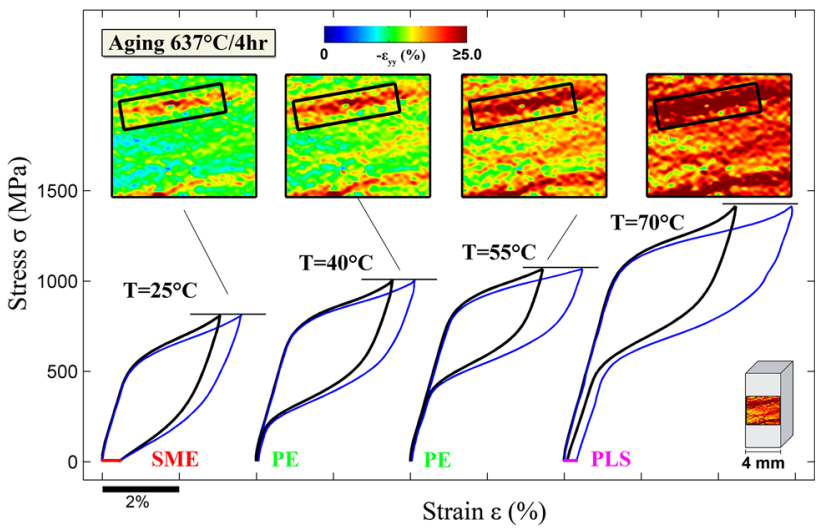

Fig. 7 Pseudoelastic behaviors of the $\mathrm{Ni}_{51} \mathrm{Ti}_{36.5} \mathrm{Hf}_{12.5}$ alloy at various temperatures after the $637^{\circ} \mathrm{C} / 4 \mathrm{~h}$ aging treatment. The local in situ DIC strain measurement is shown in blue curve

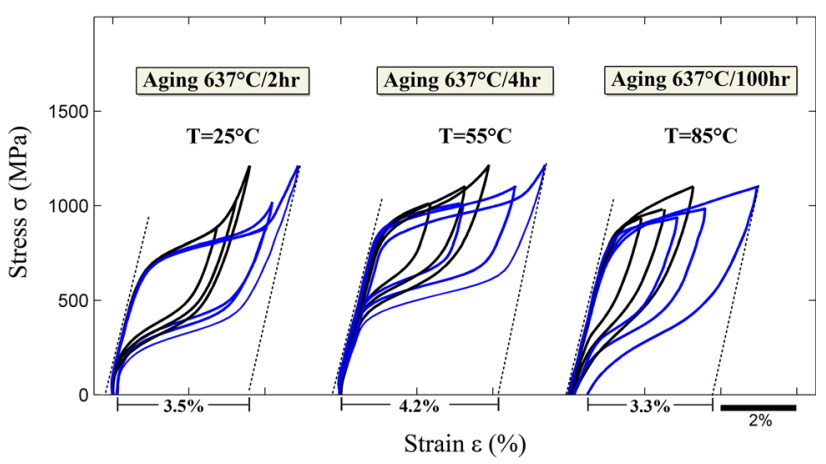

Fig. 8 Pseudoelastic behavior for three different aging treatments for the $\mathrm{Ni}_{51} \mathrm{Ti}_{36.5} \mathrm{Hf}_{12.5}$ alloy. The local in situ DIC strain measurement is shown in blue curve. This figure is significant because it points the high work output in these alloys near $50 \mathrm{~J} / \mathrm{cm}^{3}$

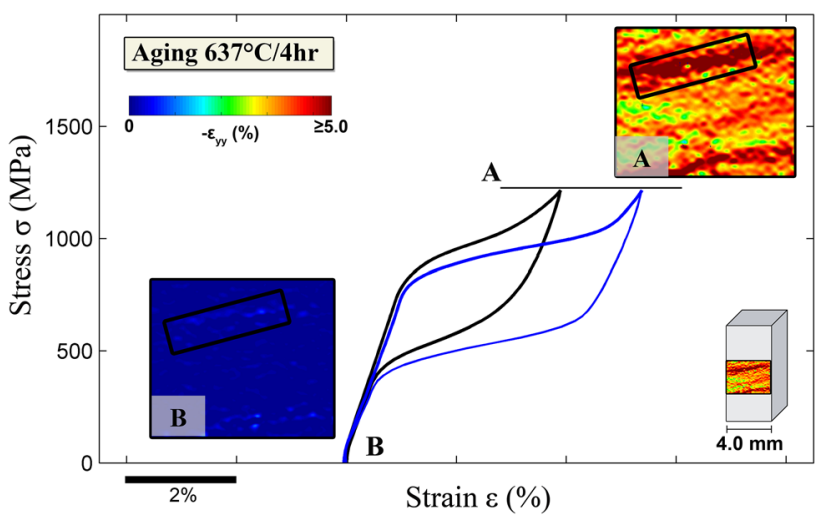

Fig. 9 The last load step at $55{ }^{\circ} \mathrm{C}$ for the $\mathrm{Ni}_{51} \mathrm{Ti}_{36.5} \mathrm{Hf}_{12.5}$ alloys aged at $637{ }^{\circ} \mathrm{C} / 4 \mathrm{~h}$ with DIC results showing strain contours at both maximum and minimum loads under compression. The local in situ DIC strain measurement is shown in blue curve

In Fig. 5, we report the stress-strain curves obtained during isothermal experiments in the temperature interval between pure martensite deformation and pure austenite 


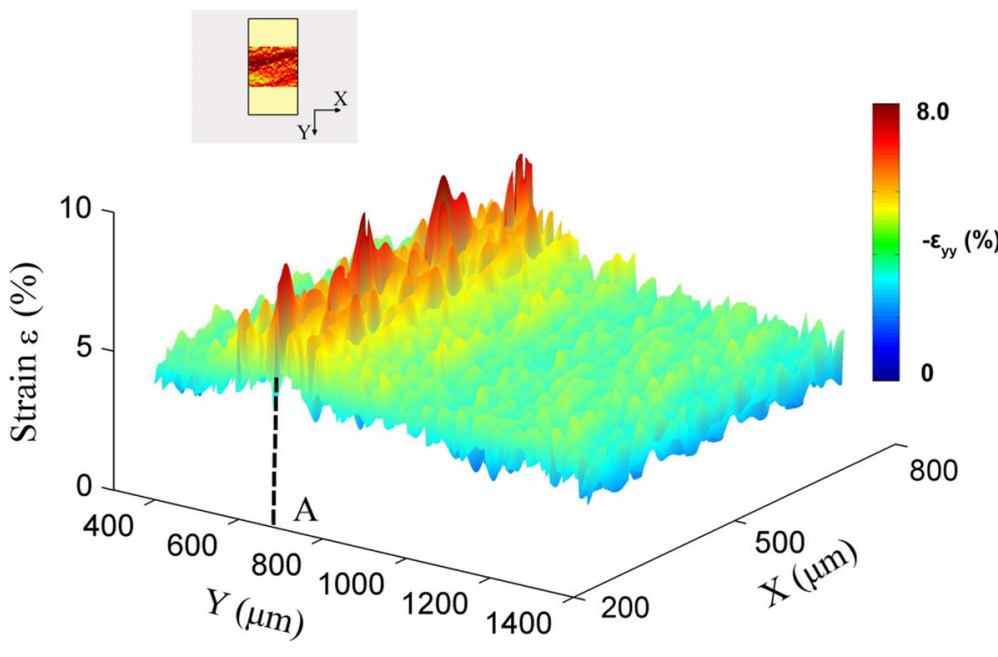

(a)

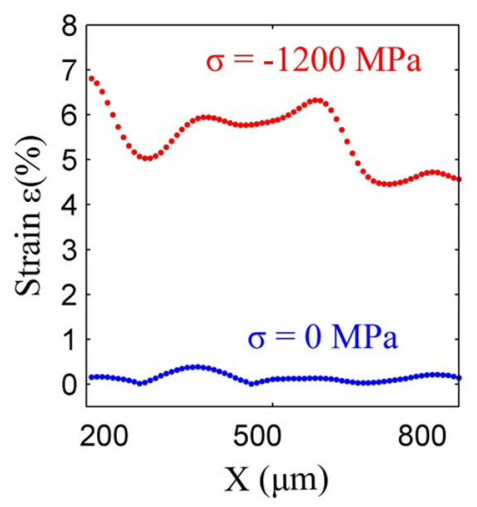

(b)

Fig. 10 a Three-dimensional illustration of the strain contour at the peak stress, $\sigma=-1200 \mathrm{MPa}$, for $637{ }^{\circ} \mathrm{C} / 4 \mathrm{~h}$ aging, and $\mathbf{b}$ strain as a function of position in $X$ direction at the maximum and minimum load in A

deformation (slip). To gain more insight into strain heterogeneity, the black curve indicates the averaged strain over a large area on the sample $(4 \mathrm{~mm} \times 3 \mathrm{~mm})$, while the blue curve indicates the local stress-strain behavior. It is important to note that transformation is localized at small scales. The red lines underneath the stress-strain curves indicate the recoverability after the thermal cycle following heating and cooling to the test temperature at zero load. At the martensite start temperature, $40{ }^{\circ} \mathrm{C}$, the yield stress displays a minimum. The corresponding residual local strain (3\%) was then fully recovered after the heating/cooling thermal cycle. At temperatures where stressinduced martensite can be obtained $\left(85-100{ }^{\circ} \mathrm{C}\right)$, good pseudoelasticity is found and shown in Fig. 5b. Based on these results, the maximum work output can be estimated using a stress level of $1200 \mathrm{MPa}$ and a strain level of $4.4 \%$ as $50 \mathrm{~J} / \mathrm{cm}^{3}$. This magnitude exceeds the work output levels observed for other NiTiHf alloys.

The relationship between $0.1 \%$ offset flow stress and temperature is plotted in Fig. 6. A linear relationship with a slope of $14.5 \mathrm{MPa} /{ }^{\circ} \mathrm{C}$ between flow strength and temperature is shown. The stress corresponding to the $M_{\mathrm{d}}$ temperature is nearly $1200 \mathrm{MPa}$ which is substantial. The transformation temperatures are marked in the figure. In the inset, similar relationships for NiTi [14] and $\mathrm{NiTiCu}_{9}$ [15] are presented to provide an insight into the comparison of flow stress among the three materials.

The pseudoelastic behavior for shorter aging treatment times, $637{ }^{\circ} \mathrm{C} / 4 \mathrm{~h}$ and $637^{\circ} \mathrm{C} / 2 \mathrm{~h}$, was also investigated. The stress-strain characterizations obtained through isothermal tests are shown in Fig. 7. As shown, when a $4 \mathrm{~h}$ aging treatment is implemented, near-perfect pseudoelastic behavior was obtained at relatively lower temperatures. Perfect pseudoelastic behavior is captured at both 40 and $55{ }^{\circ} \mathrm{C}$ for $637{ }^{\circ} \mathrm{C} / 4 \mathrm{~h}$ heat treatment. At $70{ }^{\circ} \mathrm{C}$, irrecoverable processes (slip of austenite and/or slip of transformed martensite) occur and small residual strains were measured upon unloading. The shape memory effect is obtained at room temperature for this heat treatment. It is also interesting to observe that pseudoelastic behavior is captured at $40{ }^{\circ} \mathrm{C}$ which is below austenite finish temperature, approximately $60{ }^{\circ} \mathrm{C}$.

In Fig. 8, the pseudoelastic behaviors for different aging treatments at different load steps were reported and compared. The temperatures selected for the tests were all at $A_{\mathrm{f}}-5^{\circ} \mathrm{C}$. In all three cases, pseudoelasticity was captured at a relatively high stress level above $800 \mathrm{MPa}$. The overall strains recovered at a same stress level are similar for all three cases. When a compressive stress of $1200 \mathrm{MPa}$ is applied, maximum total strain in the order of 5 and $5.5 \%$ are recovered locally upon unloading for the $637^{\circ} \mathrm{C} / 2 \mathrm{~h}$ and $637^{\circ} \mathrm{C} / 4 \mathrm{~h}$ aging, respectively. For these aging treatments, the transformation strain is determined to be 3.5 and $4.2 \%$ as shown in Fig. 8. No apparent irreversibility was observed as well. On the other hand, at the similar stress level, obvious plastic strain, $0.5 \%$, is accumulated locally for the $637^{\circ} \mathrm{C} / 100 \mathrm{~h}$ aging. The plastic strain accumulation due to long-time aging also verifies the fact that over-aging would deteriorate the pseudoelasticity.

The strain contour plots captured at the maximum and minimum load are shown in Fig. 9 for the $637{ }^{\circ} \mathrm{C} / 4 \mathrm{~h}$ aging treatment. The amount of total strain in the order of $4.4 \%$ is fully recovered, while $3.3 \%$ of which is due to phase 
Fig. 11 The stereographic triangle of the a CVP, $\mathbf{b}$ LDT strains, $\mathbf{c}$ bright field image, d corresponding electron diffraction pattern showing $(011)_{\mathrm{B} 19^{\prime}}$ Type I twin and four variants of precipitate $(P)$, e HAADF-STEM image, and f its inverse fast Fourier transformed image showing mirror symmetry of lattice planes with respect to $(011)_{\mathrm{B} 19^{\prime}}$

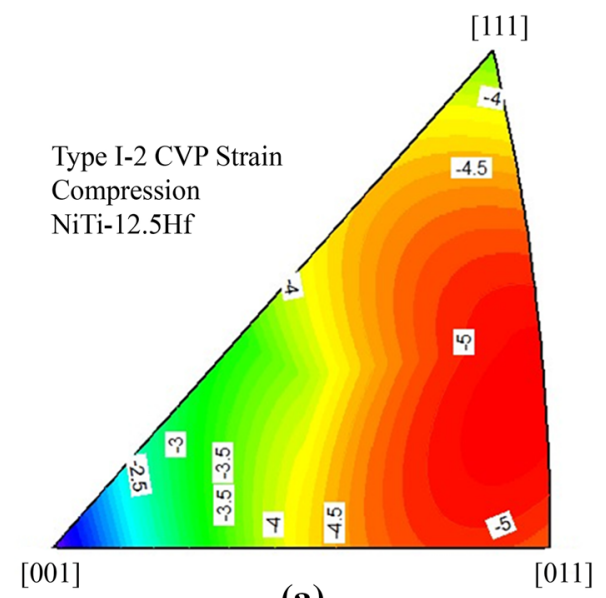

(a)

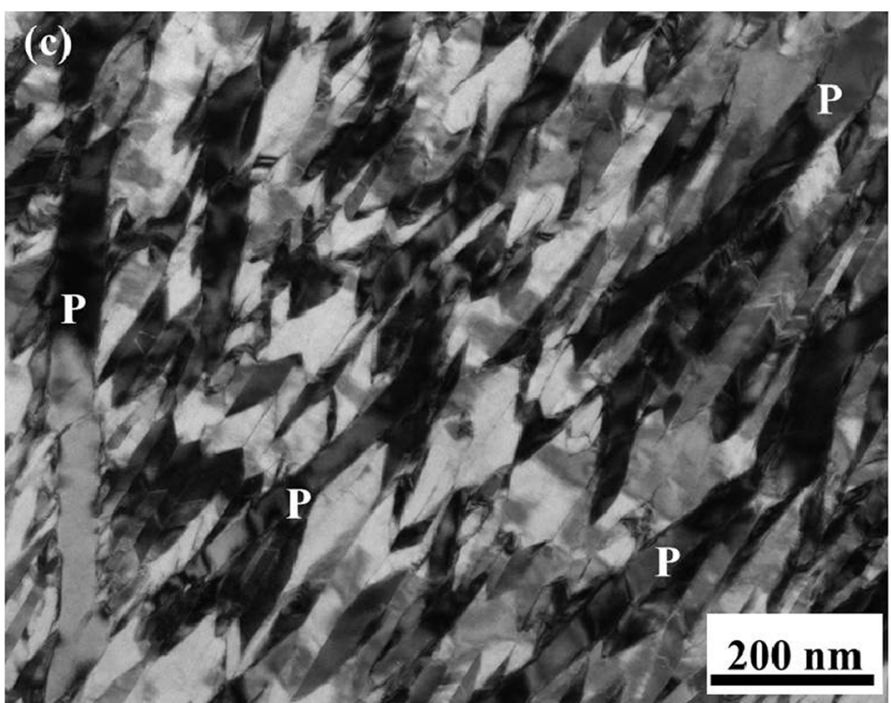

[111]

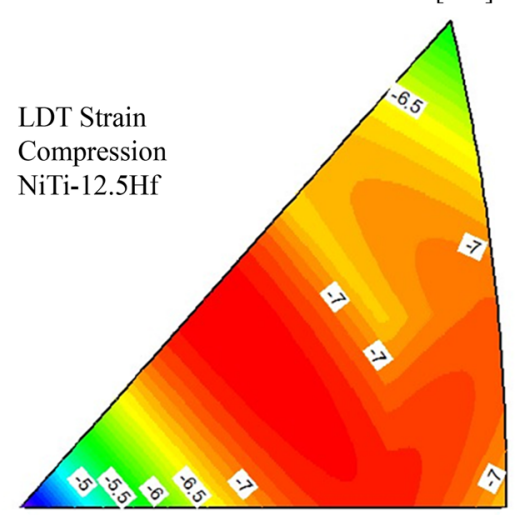

(b)
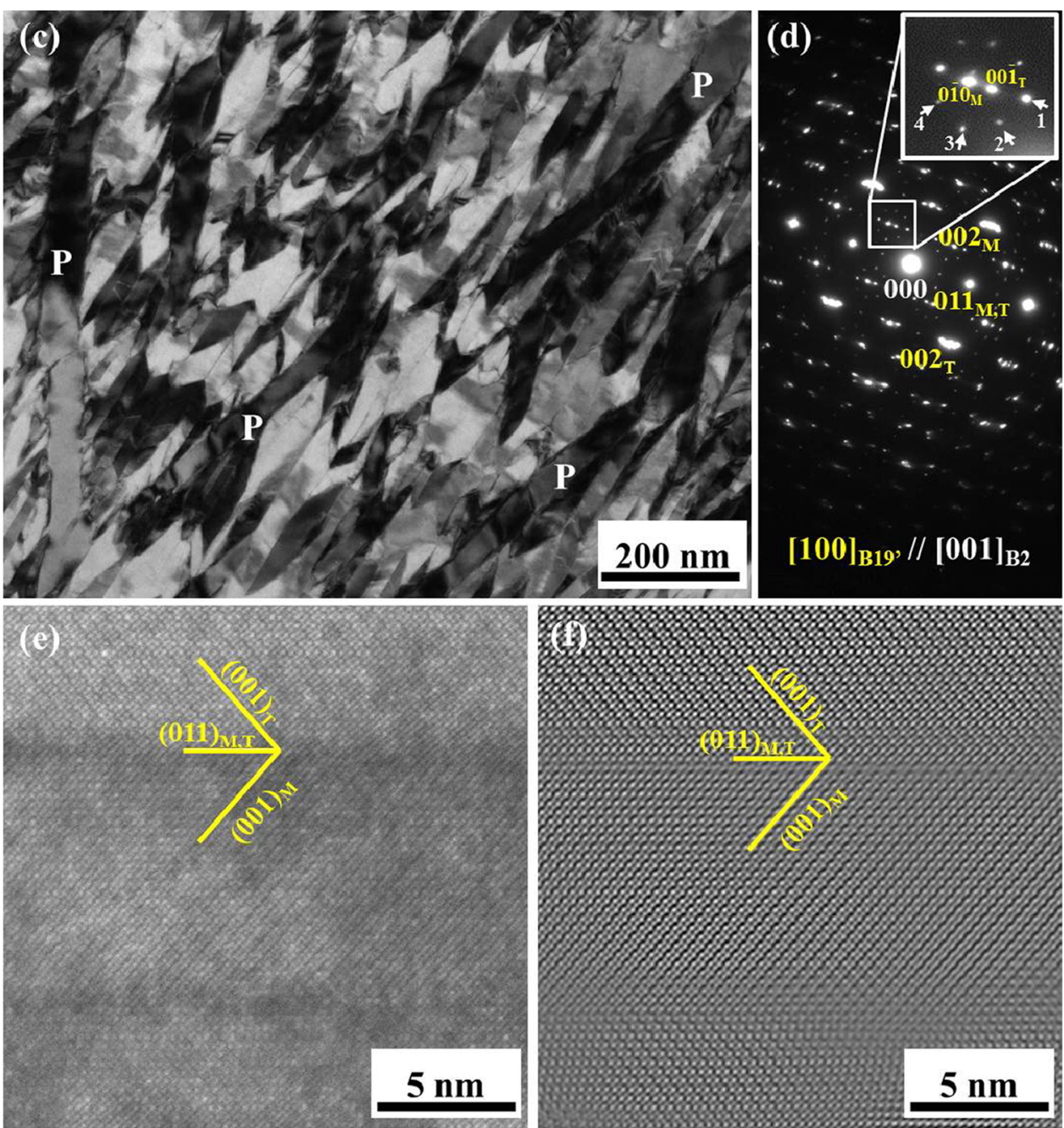

transformation. In addition to the pseudoelastic behavior, the hysteresis is found to be the lowest for the $637{ }^{\circ} \mathrm{C} / 4 \mathrm{~h}$ case among all. In the DIC images that are shown in Figs. 5, 7, and 9, the transformation strain distribution in this material is not uniform. In order to appreciate such phenomenon explicitly, a three-dimensional illustration of the axial strain contour is reconstructed into Fig. 10a. At the maximum and minimum load, an averaged strain over the peak area $A$ is plotted as a function of positions in $X$ direction in Fig. 10b. The local strains pointwise reach $6 \%$ levels. 
Fig. 12 a Bright field image and $\mathbf{b}$ corresponding electron diffraction pattern showing three sets of $(001)_{\mathrm{B} 19^{\prime}}$ compound twin and $1 / 3 \quad 110_{\mathrm{B} 2}^{*}$ type reflections derived from precipitate $(P)$
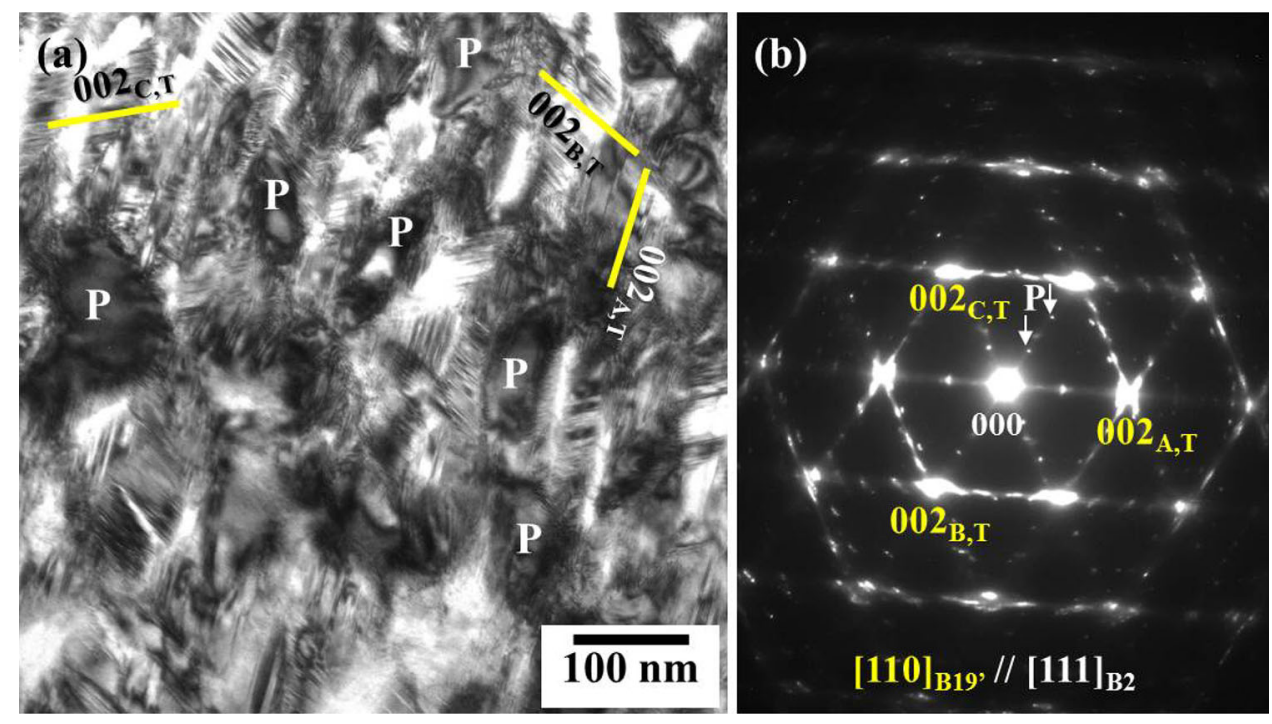
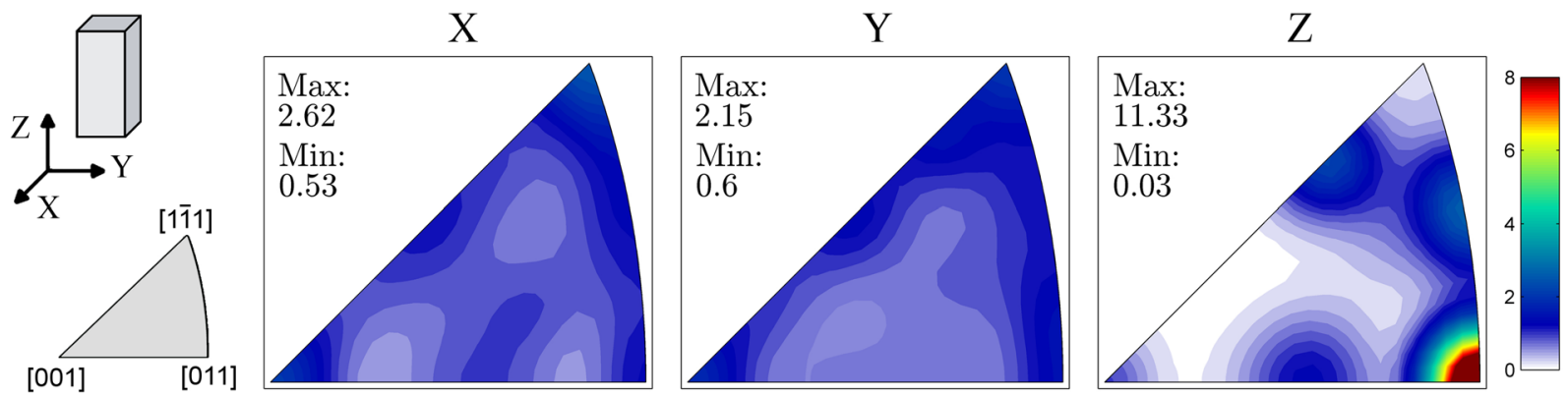

Fig. 13 The measured polycrystalline texture in NiTi12.5Hf. The measured texture favors $\langle 011\rangle$ aligned grains in the loading direction $(Z$ axis $)$

\section{Calculations of Transformation Strains and High- Resolution Electron Microscopy}

To gain further insight into the NiTi12.5Hf transformation behavior, the theoretical transformation strains were calculated using the following lattice constants. For austenite $a_{0}=0.3075 \mathrm{~nm}$, and for the monoclinic martensite $a=0.2970 \mathrm{~nm}, \quad b=0.4060 \mathrm{~nm}, \quad c=0.4770 \mathrm{~nm}, \quad$ and monoclinic angle $=98.9^{\circ}[12]$. The correspondence variant pair (CVP) formation strain (for Type I-2 twinning) and the LDT strains were established using similar procedures as outlined in [9]. Figure 11a, b provides the transformation strains for CVP and LDT, respectively. The results show maximum transformation strains of $7 \%$. Figure $11 \mathrm{c}$ shows the bright field image and Fig. 11d illustrates its corresponding electron diffraction pattern in the $\mathrm{Ni}_{51}$. $\mathrm{Ti}_{36.5} \mathrm{Hf}_{12.5}$ aged at $637{ }^{\circ} \mathrm{C}$ for $100 \mathrm{~h}$. The pattern consists of two sets of $[100]_{\mathrm{B} 19^{\prime}}$ reflections with the $(011)_{\mathrm{B} 19^{\prime}}$ Type I twin relation. Since the sharp line contrast between alternate platelets in (c) is parallel to the trace of $(011)_{\mathrm{B} 19^{\prime}}$, the platelets are in $(011)_{\mathrm{B} 19^{\prime}}$ Type I twin relation. This twin relation is clearly confirmed in HAADF-STEM and its inverse fast Fourier transformed images in (e) and (f), respectively. From the electron diffraction experiments, the structure of precipitate is the same as that reported by Santamarta et al. [16]. There are four sets of precipitate marked as $1,2,3$, and 4 around $0 \overline{1} 0_{M}$ and $00 \overline{1}_{T}$ spots in the enlarged pattern inserted in the upper right corner in (d) [16]. Figure $12 \mathrm{a}, \mathrm{b}$ indicates that there are three sets of B19' martensite plate consisting of $(001)_{\mathrm{B} 19^{\prime}}$ compound twins marked as $\mathrm{A}, \mathrm{B}$, and $\mathrm{C}$. There are also $1 / 3110_{\mathrm{B} 2}^{*}$ type reflections derived from precipitate marked as $\mathrm{P}$ in (b). The interfaces between three martensite plates are not straight and sharp in comparison to those in $\mathrm{Ni}_{50.7} \mathrm{Ti}_{29.3} \mathrm{Hf}_{20}$ alloy furnace cooled from $1000{ }^{\circ} \mathrm{C}$.

The X-ray diffraction results are shown in Fig. 13 where the $Z$ direction represents the loading axis of the specimen. The results show a preferential texture with a higher volume fraction of grains in $\langle 011\rangle$ direction. The local transformation strain measured through experiment $(\sim 6 \%$ considering the uncertainty of the strain measurements, as reported in Table 1) is in a good agreement with theoretical 
Table 1 Comparison of experimental and theoretical transformation strains for NiTi12.5Hf

\begin{tabular}{lll}
\hline Material (polycrystalline) & Experimental compressive transformation strain & Theoretical compressive transformation strain \\
\hline NiTi12.5Hf & $5.5 \pm 0.5 \%$ (Local DIC area) & $6.8 \%$ (Local, $\langle 011\rangle$ pole) \\
\hline
\end{tabular}

The results show that the local strain measurements and theory are close to each other while the entire DIC area gives a smaller average strain compared to theory (CVP strain)

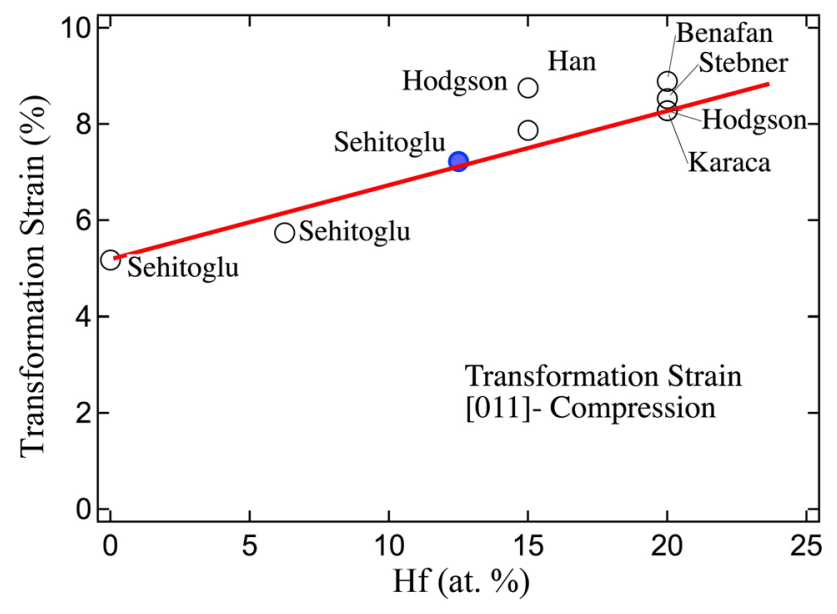

Fig. 14 The variation of transformation strain in [011] direction as a function of $\mathrm{Hf}$ content in NiTiHf alloys. The result of the present material 12.5 at.\%. Hf is shown with a blue marker. Note that lattice constants from several investigators are utilized to calculate the strains. The 6.25 and 12.5 at.\% Hf lattice constants are obtained from DFT calculations

calculation of transformation strain for the $\langle 011\rangle$ pole, which is $6.8 \%$. Theoretical values are still difficult to be matched as the DIC strain measurements provided in this study do not reach the nano-scales. Such resolution would be required in order to avoid the effect of the non-transforming precipitates. As stated earlier, the NiTiHf alloys attain higher transformation strains based on theoretical calculations compared to the binary $\mathrm{NiTi}$ case. This is illustrated in Fig. 14 where the transformation strains are shown as a function of increasing $\mathrm{Hf}$ content. The results for [011] compression are computed because this is the pole that produces higher strains in compression compared to others. In Fig. 14, the lattice constants (cubic austenite and monoclinic martensite crystals) are either obtained from X-ray diffraction in previous studies or from density functional theory $[6-9,12,17]$. We note that the 12.5 at.\% $\mathrm{Hf}$ represents a median strain in the range of alloys in Fig. 14. Three transformation strains, CVP strain and CVP + detwin strain, LDT theory strains, have been computed. The results shown in Fig. 14 represent the transformation strain calculated from the LDT theory. The differences between these three strain measures are not high in compression [9]. The straight line in Fig. 14 is drawn to aid the eye.

\section{Summary and Discussion of Results}

The work explored the underpinnings of NiTi12.5Hf transformation strains with experiments and theory. Precise local measurements are needed during the experiments to gain a true measurement of the transformation strains. Because of large domains of untransformed material, the overall transformation strains could be lower than theory, while the local levels are in agreement with theory. The maximum local measured strain levels reached $7 \%$ (Fig. 10) which exceeds the level in other NiTiHf studies. The results also point to the importance of characterization of the microstructure establishing the type of twinning of the martensite and the volume fraction of precipitates. This knowledge represents an important step to make comparisons between theory and experiment. Since the precipitates cannot transform, the measured strain levels can be lower than expected.

The shape memory and pseudoelasticity response of the new shape memory alloy $\mathrm{Ni}_{51} \mathrm{Ti}_{36.5} \mathrm{Hf}_{12.5}$ were chosen because it permitted studies of shape memory and pseudoelasticity without premature fracture. Hence, the flow stress behavior (Fig. 4) near the $M_{\mathrm{d}}$ temperatures can be measured readily and compared to binary $\mathrm{NiTi}$ and other NiTiX alloys. As pointed earlier, the Hf provides a stronger strengthening element compared to $\mathrm{Fe}, \mathrm{Cu}$, and $\mathrm{Pd}$ [12]. The flow stress levels were near $1200 \mathrm{MPa}$ for the NiTi12.5Hf alloy and using a macroscopic strain of $3.5 \%$ results in a high work output (near $50 \mathrm{~J} / \mathrm{cm}^{3}$ ) which is likely the highest among transforming alloys. While the $\mathrm{NiTi}$ alloys with high $\mathrm{Ni}$ contents [18] also exhibit high flow stresses, the transformation strains are less than $3.5 \%$ in those cases.

During studies on shape memory alloys, it is important to seek treatments to achieve the optimum levels of transformation strains, transformation temperatures, and temperature hysteresis. We note that transformation temperatures of this material were investigated with various aging treatments $\left(637{ }^{\circ} \mathrm{C}\right)$ ranging from 1 to $100 \mathrm{~h}$. We observe that the transformation temperatures rapidly increase with aging time from 1 to $10 \mathrm{~h}$, reaching saturation at longer aging times beyond $10 \mathrm{~h}$ (see Fig. 1a, b for details) with austenite peak temperatures near $100{ }^{\circ} \mathrm{C}$.

For the heat treatment at $637^{\circ} \mathrm{C}$ for $100 \mathrm{~h}$, the shape memory property was investigated during isobaric experiments at different stress levels. The material possessed 
small residual strain up to $-500 \mathrm{MPa}$. In Fig. 4 , the maximum strain was in the order of $7 \%$ locally and later fully recovered upon heating. This is comparable to the strain level predicted based on the LDT theory utilizing the lattice constants of austenite and martensite phases. It was clear from the DIC results that the grains which yield the highest transformation strain do not extend to the entire specimen. The shape memory effect and pseudoelasticity were also investigated via isothermal compression tests at different temperatures as shown in Fig. 5. Pseudoelasticity extended to $115^{\circ} \mathrm{C}$ in this class of alloys. As the temperature increases, excellent pseudoelastic behavior was found at 85 and $100{ }^{\circ} \mathrm{C}$. The plastic irreversible strains developed beyond $115{ }^{\circ} \mathrm{C}$. Similarly, further efforts are required to capture sub-grain deformation which would enable strain measurements at higher resolution and potentially match with theoretical transformation strains levels in other NiTiHf alloys.

As shown in Fig. 10, the strain distribution is inhomogeneous with maximum localized strains exceeding $6 \%$. Higher transformation strains are favored near the [011] pole with much lower strain near [001] with [111] being the intermediate (Fig. 11a, b). Measurements with X-ray diffraction on our samples confirm the preference for grains in $\langle 011\rangle$ direction. It is important to note that for the case of increasing hafnium, the monoclinic angle increases (from $96.8^{\circ}$ for NiTi to $98.9^{\circ}$ for NiTi12.5Hf) which in turn increases the transformation strains. In general, the high compressive strain values relative to the binary NiTi could be an important advantage of the high Hf-rich alloys in addition to the elevated temperature capability. We note, however, the results point to a large reduction in strains at the macroscale, i.e., polycrystalline experimental strains are near $3.5 \%$. This is attributed to the presence of untransforming domains.

Comparing NiTiHf alloys to other ternary shape memory alloys, the strengthening associated with $\mathrm{Hf}$ is significant. In fact, the flow stress rises with increasing Hf content and reaches a saturation at higher Hf contents [12] (see Fig. 7). Therefore, the flow stress and transformation strain combination appear to be very attractive for lower $\mathrm{Hf}$ contents such as 12.5 at.\% Hf though the choice of $\mathrm{Hf}$ could depend on the application. The predicted transformation strains for NiTiHf alloys, are higher than $\mathrm{NiTiCu}$ [18] and NiTiFe alloys, and also with higher temperature capability as discussed above.

We provided a comparison of the transformation strain calculations for compression in Fig. 14 for the $\langle 011\rangle$ direction. The results show unequivocally the elevation of the transformation strains with increasing Hf content. Such an increase can be exploited to design potentially NiTiHf compositions with higher transformation strain levels by modifications in crystallographic texture and $\mathrm{Hf}$ contents.
One of the issues is clearly the heterogeneity in the transformation at the macroscale which needs to be further explored in other Hf alloys.

Overall, the work underscores the need for a multifaceted approach combining (i) precise determination of the values of lattice constants with diffraction methods or electronic structure calculations, (ii) high-resolution microcopy to identify twin types and volume fraction of precipitates, (iii) measurements of local strains in a heterogeneous environment, and (iv) phenomenological martensite strain calculations to gain a stronger understanding of the behavior of NiTiHf alloys. The results point to the need for a better understanding of transformation strain progression during transition from small to large scales in future studies and to ascertain the role of grain boundaries on the advance of transformation fronts in NiTiHf class of alloys.

\section{Conclusions}

The work demonstrated the following conditions:

(1) In NiTi12.5Hf alloy, local strain measurements with DIC result in high transformation strains and provide an intrinsic measure of transformation since domains of transformed and untransformed material co-exist in NiTiHf alloys. At the local level, the strains can reach $6 \%$ in experiments which agrees with transformation strain predictions near the $\langle 011\rangle$ pole $(\sim 6.7 \%)$. When larger volumes are considered, the measured transformation strains fall to $3.5 \%$.

(2) In the NiTi12.5Hf alloy, the transformation stress levels approached $1200 \mathrm{MPa}$ in compression, and with macroscopic strain levels of $3.5 \%$, the work output of such alloys is near $50 \mathrm{~J} / \mathrm{cm}^{3}$. This level of work output exceeds the higher Hf alloys where the stresses are similar while the experimental strains are much smaller. Compared to binary NiTi alloys, the work output is also higher in compression.

(3) A thorough microstructural characterization utilizing (SEM), (TEM), (STEM), and X-ray diffraction was undertaken to gain a better understanding of the NiTi12.5Hf. The X-ray diffraction studies pinpointed the strong preference for $\langle 011\rangle$ grains supporting the high strain measurements locally. The microscopy observations provided quantitative insight into the precipitate volume fraction and the twinning type in this alloy.

Acknowledgments The work was supported by NSF-CMMI 1333884 which is gratefully acknowledged. The authors also acknowledge the Frederick Seitz Materials Research Laboratory and Dr. Mauro Sardela for assistance with X-ray diffraction. 


\section{References}

1. Funakubo H (1987) Shape memory alloys. Gordon and Breach Science Publishers, Amsterdam (translated from the Japanese by Kennedy JB)

2. Otsuka K, Wayman CM (1998) Shape memory materials. Cambridge University Press, Cambridge

3. Van Humbeeck J (1999) High temperature shape memory alloys. J Eng Mater Technol 121:98-101

4. Ma J, Karaman I, Noebe RD (2010) High temperature shape memory alloys. Int Mater Rev 55:257-315

5. Bigelow GS, Garg A, Padula Ii SA, Gaydosh DJ, Noebe RD (2011) Load-biased shape-memory and superelastic properties of a precipitation strengthened high-temperature $\mathrm{Ni}_{50.3} \mathrm{Ti}_{29.7} \mathrm{Hf}_{20}$ alloy. Scr Mater 64:725-728

6. Karaca HE, Saghaian SM, Basaran B, Bigelow GS, Noebe RD, Chumlyakov YI (2011) Compressive response of nickel-rich NiTiHf high-temperature shape memory single crystals along the [111] orientation. Scr Mater 65:577-580

7. Benafan O, Garg A, Noebe RD, Bigelow GS, Padula Ii SA, Gaydosh DJ et al (2014) Mechanical and functional behavior of a Ni-rich $\mathrm{Ni}_{50.3} \mathrm{Ti}_{29.7} \mathrm{Hf}_{20}$ high temperature shape memory alloy. Intermetallics 50:94-107

8. Stebner AP, Bigelow GS, Yang J, Shukla DP, Saghaian SM, Rogers $R$ et al (2014) Transformation strains and temperatures of a nickel-titanium-hafnium high temperature shape memory alloy. Acta Mater 76:40-53

9. Sehitoglu H, Karaman I, Anderson R, Zhang X, Gall K, Maier H et al (2000) Compressive response of NiTi single crystals. Acta Mater 48:3311-3326
10. Patriarca L, Sehitoglu H (2015) High-temperature superelasticity of $\mathrm{Ni}_{50.6} \mathrm{Ti}_{24.4} \mathrm{Hf}_{25.0}$ shape memory alloy. Scr Mater 101:12-15

11. Sutton MA, Orteu JJ, Schreier H (2009) Image correlation for shape, motion and deformation measurements: basic concepts, theory and applications. Springer, New York

12. Wang J, Sehitoglu H (2014) Modelling of martensite slip and twinning in NiTiHf shape memory alloys. Philos Mag 94:2297-2317

13. Han XD, Wang R, Zhang Z, Yang DZ (1998) A new precipitate phase in a TiNiHf high temperature shape memory alloy. Acta Mater 46:273-281

14. Jacobus K, Sehitoglu H, Balzer M (1996) Effect of stress state on the stress-induced martensitic transformation in polycrystalline Ni-Ti alloy. Metall Mater Trans A 27:3066-3073

15. Sehitoglu H, Karaman I, Zhang X, Kim H, Chumlyakov Y, Kireeva I et al (2001) Deformation of NiTiCu shape memory single crystals in compression. Metall Mater Trans A 32:477-489

16. Santamarta R, Arróyave R, Pons J, Evirgen A, Karaman I, Karaca HE et al (2013) TEM study of structural and microstructural characteristics of a precipitate phase in Ni-rich $\mathrm{Ni}-\mathrm{Ti}-\mathrm{Hf}$ and $\mathrm{Ni}-$ Ti-Zr shape memory alloys. Acta Mater 61:6191-6206

17. Potapov P, Shelyakov A, Gulyaev A, Svistunov E, Matveeva N, Hodgson D (1997) Effect of $\mathrm{Hf}$ on the structure of $\mathrm{Ni}-\mathrm{Ti}$ martensitic alloys. Mater Lett 32:247-250

18. Sehitoglu H, Karaman I, Zhang X, Viswanath A, Chumlyakov Y, Maier HJ (2001) Strain-temperature behavior of $\mathrm{NiTiCu}$ shape memory single crystals. Acta Mater 49:3621-3634 